\title{
Expressing Opinions About the Refugee Crisis in Europe: The Spiral of Silence and Crisis Communication
}

\author{
Bengt Johansson \\ Department of Journalism, Media, and Communication, University of \\ Gothenburg, Gothenburg, Sweden
}

\begin{abstract}
Framing of crisis events is to a large extent contested, with multiple sources and conflicting messages. Theories of crisis communication acknowledge how people try to deal with these competing messages, and this article seeks to deepen the understanding the process of sense making of crisis events by connecting crisis communication to the spiral of silence theory. The spiral of silence theory, founded by Elisabeth Noelle-Neuman, proposes that people are less willing to express their opinions if they believe their beliefs are shared by a minority. This will lead to a spiral in which those who feel their opinions are popular are more inclined to express their opinions, and those who perceive their opinions are unpopular among the public become more silent. This study analyzed changes over time in the willingness to express opinions about the refugee crisis in Europe using a two-wave Web-panel survey $(N=1,185)$ in Sweden in 2015-2016. The focus is the impact of changing government policy, which moved from a generous refugee policy toward a more restrictive policy. Changes toward a more restrictive refugee policy did not seem to change the overall picture. Those supporting a more restrictive policy were still less inclined to speak their true opinions about the refugee crisis, even if the policy had changed in their favor. On the other hand, respondents supporting a more generous refugee policy seemed to become more cautious about expressing their opinions about the refugee crisis after the policy change, especially when talking to strangers.
\end{abstract}

KEYWORDS: Spiral of silence; crisis communication; opinion change; refugee crisis; interpersonal communication

Framing of crisis events is to a large extent contested (Boin, t'Hart, \& McConnell, 2009; Frandsen \& Johansen, 2017; Seeger \& Sellnow, 2016). Even if risk and crisis communication research largely focus on how to create best practices for designing and disseminating crisis communications and reaching a common public understanding of

CONTACT Bengt Johansson, PhD•E-mail: bengt.johansson@jmg.gu.se • University of Gothenburg, Box 710, 40530 Gothenburg, Sweden

@ 2018 by Journal of International Crisis and Risk Communication Research. All rights reserved. 
crisis situations, it is also pointed out that crisis events take place in situations of framing contest (Frandsen \& Johansen, 2017; Heath \& O'Hair, 2010; Seeger \& Sellnow, 2016). Questions of contest can be, Is there actually a crisis going on? Who is responsible for the upcoming situation? How can it be solved? What is the proper way of dealing with the crises? These questions will be addressed by decision makers, organizations, news media, and citizens, and crisis decisions are thus made in an environment of competing messages (Boin, t'Hart, Stern, \& Sundelius, 2005).

When discussing citizens' perceptions of crisis events, we have to consider how this frame contest affects the sense making of a crisis. Risk and crisis communication has shown how people use different strategies to make sense of an uncertain situation (Sellnow \& Seeger, 2013; Vigsø \& Odén, 2016). One example of these strategies is convergence theory, which focuses on the ways in which individuals make sense of competing information by collecting and contemplatinge information from different sources and discussing this information with family, friends, and neighbors (Anthony, Sellnow, \& Millner, 2013; Sellnow, Ulmer, Seeger, \& Littlefield, 2009). However, one possible problem with the process of sense making might be that all these communication opportunities are not always at hand. In crises with competing frames, people might not always be comfortable expressing what they really think about different aspects of the crisis. Some speak out and discuss controversial issues with their families, friends at work, or even people they do not know. Others stay silent and are afraid to let others know what they really think about the issue at hand.

This article seeks to deepen the understanding the process of sense making of crisis events by connecting crisis communication to the spiral of silence theory. Even if theories of crisis communication acknowledge that people try to deal with competing messages, it has not taken into consideration the social dynamics of the sense-making process. The spiral of silence might be a way to further understand how people react to and communicate in times of crisis. 


\section{Literature Review}

\section{The Spiral of Silence}

The spiral of silence theory proposes that people are less willing to express their opinions when they believe their beliefs are shared by a minority (Noelle-Neuman, 1984). We are sensitive to our surrounding social environment and will not speak out if we fear becoming socially isolated. This will lead to a spiral in which those who feel their opinions are popular are more inclined to express their opinions and those who perceive their opinions are unpopular among the public become more silent.

The spiral of silence is seen as one of the most influential theories of communication and political communication over the last halfcentury (Donsbach, Salmon, \& Tsfati, 2016) and has been tested in numerous studies. The general conclusion of meta-analyses shows a general but weak relationship between the perceived opinion climate and respondents' willingness to express their opinions (Glynn, Hayes, \& Shanahan, 1997; Glynn \& Huge, 2016).

But the theory has been criticized and studies have been contested for a number of reasons. The spiral of silence theory is so complex and contains so many assumptions that the whole theory has never been (and probably never will be) comprehensively tested (Matthes \& Hayes, 2016). Scholars have, over the years, separated the model into manageable parts, but still, after almost 40 years of research, we find research criticizing everything from the assumptions and the generalizability to the design and how to measure key concepts of the theory (Hayes, 2007; Matthes \& Hayes, 2016; Neuwirth, Frederick, \& Mayo, 2007).

One major critical point in previous research is how research has failed to capture the dynamics of the theory. As Matthes and Hayes (2016) argued, research has neglected to observe the spiral in the theory because of improper research design. Most studies use cross-sectional data or aggregate data; the former can only capture a frozen moment of the phenomena, and the latter have an ecology fallacy problem (Matthes \& Hayes, 2016). Whether people actually change their willingness to speak out because of the opinion climate is, to a large extent, still unknown. 
As stated previously, the general aim of this article is to use the spiral of silence in studying crisis communication, but the purpose is also to deepen the knowledge of the dynamics of the spiral of silence theory. Therefore this work builds on panel data from Sweden in 2015 and 2016 in which respondents were asked questions about their willingness to express their opinions about the refugee crisis in Europe.

The Swedish government changed its refugee policy from an "opendoor policy" to one of the most restrictive in Europe in late fall 2015 (Ghersetti \& Odén, in press). ${ }^{1}$ Because of the policy change, we are able to measure people's readiness to share opinions about the refugee crisis just before the policy changed and after the change was made. This makes it possible to evaluate whether respondents changed their willingness to speak out when the opinion climate changed.

By studying the refugee crisis, the study also fulfills one of the important assumptions of the spiral of silence-the requirement of a value-laden issue. Immigration and refugees have a strong moral component and are controversial and therefore in line with NoelleNeuman's argument that it is only from a moral or normative element that one can fear the threat of isolation (Gearhart \& Zhang, 2015; Noelle-Neuman, 1984; Scheufele \& Moy, 2000). This will of course also be a good example of an issue were there are competing frames and opinions. The empirical aim is therefore to analyze to what extent individuals change their willingness to express their opinions when government policy concerning a value-laden issue changes.

The organization of the article is as follows. The next section reviews the key assumptions and results of spiral of silence research. This framework is used in more detail to discuss some shortcomings and criticisms of spiral of silence research. On the basis of previous findings, a number of hypotheses are proposed, and thereafter the methodology and measures used in the study are described. After presenting the results, the article ends with conclusions, a discussion of the limitations of the study, and implications of the results for crisis communication.

\section{The Spiral of Silence: Theory and Previous Findings}

One of the important needs of the spiral of silence theory is a value-laden issue. As said earlier, fear of isolation is only relevant when the question 
at hand is controversial. In spiral of silence research, immigration is categorized as a transitory issue (Gearhart \& Zhang, 2015). Transitory issues are not constantly in the public eye but reemerge from time to time. The issue salience of immigration has increased during the last decade in Sweden and Europe in general (Green-Pedersen \& Krogstrup, 2008). Immigration in 2015 was, for the first time, viewed as the most important societal issue among Swedish citizens (53\% mentioned immigration as an important societal issue; Ohlsson, Ekengren, \& Solevid, 2016), and immigration was also the most prominent issue during the 2014 election campaign in the news media (Johansson, 2017). Analyses of the news media content of the election also indicates a strong focus on immigration, and the refugee crisis was the dominant news story during fall 2015 (Ghersetti \& Odén, in press).

Some studies of the spiral of silence have focused on immigration to test the theory. Matthes, Morrison, and Schemer (2010) analyzed the national referendum about the naturalization of Swiss immigrants. The results provided empirical support because those perceived as being a minority expressed their opinions to a lesser extent. This tendency was especially prevalent among those who were less convinced of their opinions. Similar empirical support was also found in a study using Asian immigration to Australia as a case (Louis, Duck, Terry, \& Lalonde, 2010). Gearhart and Zhang (2015) also included a question on immigration (if undocumented immigrants should have the opportunity to receive permanent residency) when testing different types of issues and the spiral of silence theory. The authors found robust support for the spiral of silence theory related to both immigration and the other investigated issues (abortion and gay marriage).

A recurrent criticism of spiral of silence research is the lack of longitudinal studies. In most cases, research uses cross-sectional data and can only, as Matthes and Hayes (2016) put it, analyze the social conformity hypothesis. Cross-sectional data measure at a single moment the difference between respondents expressing their opinions and those being silent. However, this does not capture the dynamics of opinion change, which is one of the central aspects of the theory. To investigate if the opinion climate leads to changes in the willingness to speak out (the change hypothesis), studies over time are needed. Noelle-Neuman 
(1984) used trend survey data to demonstrate how aggregate opinions increased or decreased depending on the opinion climate. As Matthes and Hayes (2016) noted, this might give an intuitive understanding of the phenomenon, but it is not a proper way to study changes on an individual level and might also suffer from ecology fallacy. Trend survey data are therefore not appropriate to study the dynamics of the spiral of silence theory. A few studies have used panel data. Shamir (1997) used a two-wave panel to investigate the spiral of silence and climate change, and McDonald, Glynn, Kim, and Ostman (2001) used a fourwave panel from 1948 and conducted a secondary analysis on opinion climate and candidate preference.

The asylum regime in Sweden has been generous and sometimes described as an "open-door policy" (Ghersetti \& Odén, in press). The policy had broad support among the political parties, and only the nationalist-populist Swedish Democrats ( $13 \%$ in the 2014 general election) opposed the policy. It should also be noted that Swedes are more open to immigrants and welcoming refugees compared to citizens in the rest of Europe (Sides \& Citrin, 2007).

The refugee situation escalated during fall 2015, when 10,000 refugees arrived in Sweden every week and Migration Agency of Sweden estimates claimed that 190,000 would seek asylum in Sweden in 2015 (in reality, it was 162,000$).{ }^{2}$ The Dublin Convention states that refugees should seek protection in the first European Union (EU) land they enter, ${ }^{3}$ but most EU countries let refugees move to other countries. Sweden and Germany were considered popular because of their generous refugee policies, but the number of refugees caused strong tensions in the asylum-seeking process in Sweden (and Germany), not least in terms of housing. The Swedish government (a coalition of the Social Democrats and the Green Party), therefore, decided to change the policy, and in November 2015, identity checks were imposed on all modes of transport to Sweden, and the right to bring families to Sweden was severely restricted. In one day, Sweden had changed its refugee policy from being the most generous in the EU to being one of the most restrictive. The only party that opposed the new policy was the Left Party, with less than $10 \%$ support (Ghersetti \& Odén, in press). The refugee situation in Sweden (and Europe) can therefore these years be 
described in terms of a crisis as defined by Ulmer, Sellnow, and Seeger (2007): "a specific, unexpected, non-routine event or series of events that creates a high level of uncertainty and a significant or perceived threat to high priority goals" (p. 7).

From what we know from opinion research, we can expect changes in public opinion when policies change. Zaller (1992) discussed the elite dominance in the news and concluded that the public reacts to elite perspectives on information, and even if not everyone changes his or her mind, changes in elite opinions will have a major impact on citizens' views of societal issues (Zaller, 1992; see also Bennet, 1990; Iyengar \& Kinder, 1987). In fall 2015, many political parties abruptly changed their refugee policies. Results also indicate that media coverage also generally follows the framing of the changed policy (Ghersetti \& Odén, in press).

Thus, in line with the spiral of silence theory, we would, before the policy change, expect a greater willingness to express opinions about the refugee crisis among respondents supporting a more generous refugee policy compared to those holding a more restrictive view. This scenario would probably change because of the changing policy, and we would expect that those favoring a more restrictive view would be more willing to share their opinions. Following this logic, the respondents supporting a more generous policy would be silenced. The study hypotheses follow:

H1: Opinion congruency in refugee policy between respondents' opinions and government policy will be positively related to a willingness to express opinions about the refugee crisis.

H2: When government policy changes to a more restrictive refugee policy, respondents supporting a restrictive policy will increase their willingness to express their opinions about the refugee crisis.

H3: When government policy changes to a more restrictive refugee policy, respondents supporting a generous policy will decrease their willingness to express their opinions about the refugee crisis.

The spiral of silence phenomenon is generally tested on speaking out in front of unknown people ("talking to a stranger on the bus" is often used in survey questions) and is generally believed to be weaker when 
it is related to the social groups to which the individual belongs. The fear of isolation tends to be less pronounced when it comes to talking with family, friends, and work colleagues and classmates (Hampton et al., 2014). Against this background, we would expect the willingness to express an opinion about the refugee crisis to be more accepted when it comes to family and friends than other reference groups:

H4: The willingness to express opinions about the refugee crisis will be more accepted when talking to family and friends, compared with work colleagues and classmates and people respondents do not know so well.

Because the elite opinion changed and the news media seemed to report this change without challenging the dominant frame (Ghersetti \& Odén, in press), the two waves can be viewed as capturing the change in opinion climate on an aggregate level. In this sense, one could argue that the design follows Noelle-Neuman's (1984) original measure of opinion climate, where she emphasized that the opinion climate is about the factual gain or loss of ground among the population, not if the individual also perceives this process. However, in most spiral of silence research, a common way to measure the opinion climate is to ask respondents how they perceive the general opinion position on the issue and compare these answers with their own issue position (Matthes \& Hayes, 2016). Even so, there have been many suggestions about how to measure the opinion climate. Some have asked about the opinion among the general public (Shamir, 1997), while others have focused on different reference groups (Moy, Domke, \& Stamm, 2001; Oshagan, 1996). An interesting and maybe also troublesome aspect in previous research is the lack of mass media indicators in many studies. Matthes and Hayes (2016) highlighted that only a few studies actually include media content in their analyses and fail to establish a connection between the media content to which respondents are exposed and their perception of the opinion climate. However, there are a few examples of studies where the climate of opinion is measured as seen to be conveyed through the mass media (Matera \& Salwen, 1992). To arrive at a more thorough understanding of the processes, the design of this 
study also includes an analysis of those respondents who changed their inclination to speak out (see also Gearhart \& Zhang, 2015) to evaluate to what extent this disposition may be related not only to the changing opinion climate but also to perceptions of the news media's reporting (media congruency), which can be viewed as a subjective measure of the opinion climate. A proposed research question is as follows:

To what extent can respondents' willingness to express their opinions about the refugee crises be related to media congruency?

\section{Method}

To try to overcome some of the critical points referred to earlier, this study of the spiral of silence in crisis events uses (a) a two-wave panel study to be able to investigate changes in willingness to express opinions; (b) analysis of a real-world event-not a hypothetical-which makes the situation more real for respondents (see Hayes, 2007); and, because there was a dramatic change in elite opinion of the refugee issue, where all major parties changed their opinions and decided to change the policy, (c) observations of whether the change of (elite) opinion climate also affects willingness to speak out.

\section{Data Collection}

Data for this study were collected in November 2015 (before the policy change) and April 2016 (after the policy change) and were generated by the Laboratory of Opinion Research (Lore) at the University of Gothenburg using a Web survey panel of Swedish citizens. The panel contains both self-recruited respondents (approximately 60,00o) and respondents recruited from probability-based population samples (approximately 10,000). ${ }^{4}$

The chosen sample $(2,500)$ was randomly selected from the citizen panel and was stratified to reflect the general population according to gender, age, and education. The first wave of the survey was collected between October 26 and November 5, 2015, with a response rate of $63 \%$. The second wave was sent out to respondents (who answered the first survey) between April 21 and May 3, 2016. The response rate 
of the second wave was $71 \%$. In both panel waves, 1,185 respondents answered the questions.

The design using a two-wave panel (i.e., interviewing the same persons two times) enhances the possibility to track individual trajectories over time. It makes it easier to rule out other factors that might affect the results and strengthens claims of causal interpretations (Berrington, Smith, \& Sturgis, 2006).

\section{Measures}

Willingness to speak out. The criterion variable in this study was measured by three questions capturing different social spheres: (a) family and friends, (b) work colleagues and classmates, and (c) strangers. The following question was posed: "To what extent do you feel you can speak out about the refugee crisis with your family and closest friends?" Respondents were given a 5-point scale on which to place themselves, ranging from 1 (to a very large extent) to 5 (to a very small extent; Wave 1, $M=4.56, S D=0.80$; Wave 2, $M=4.57, S D=0.78)$. The same scale was used to ask if respondents were willing to speak out about the refugee crisis with people at work and in school: "To what extent do you feel you can speak out honestly about the refugee crisis with work colleagues and classmates?" (Wave 1, $M=3.87, S D=1.22$; Wave 2, $M=3.79, S D=1.21$ ).

To measure the willingness to speak out in relation to strangers, the third question asked, "To what extent do you feel you can speak honestly about the refugee crisis with people you don't know well?" Respondents were given a 5-point scale on which to place themselves, ranging from 1 (to a very large extent) to 5 (to a very small extent; Wave 1 , $M=3.21, S D=1.37$; Wave $2, M=3.04, S D=1.38$ ).

Own opinion. Respondents were asked to express their opinions about the refugee issue by measuring to what extent they would favor a more restrictive, status quo, or generous refugee policy. The question was posed, "How well do the following statements comply with what you think of the refugee reception?" Respondents answered using a 5-point scale to express their opinions about the refugee issue, ranging from 1 (we should receive far fewer refugees than today) to 5 (we should accept far more refugees than today; Wave $1, M=2.77, S D=1.42$; Wave 2, $M=2.68$, 
$S D=1.43$ ). The variable was computed as a dichotomous variable in the analysis (restrictive/generous policy opinion). Respondents with the opinion of receiving fewer refugees in both waves and being pleased with the present level in Wave 2 were considered as supporting a restrictive policy. With the same logic, respondents claiming Sweden should accept more refugees in both waves and being content with the present level of refugee reception in Wave 1 were coded as supporting a generous policy. This recoding will of course create a loss of data concerning attitude change, but the rationale is to be able to include those changing their minds due to the policy change.

Perception of media congruency. As pointed out previously, there is a discussion in spiral of silence research about the importance of perceptions of opinion climate. The measure of media congruency (evaluation of news media reporting) is viewed as an alternative way to measure the subjective perception of the opinion climate. Even if this is not a straightforward question of how a respondent's own opinion is related to the general opinion, we know from previous research that people tend to generalize media content to the general view of societal problems and their effect on public opinion (Gunther \& Storey, 2003; Perloff, 2015; Schulz \& Roessler, 2012). Evaluation of news media reporting can therefore be seen as a proxy for the respondents' views on the opinion climate in society.

The respondents were asked to evaluate the news media reporting of the refugee crisis with the question, "How do you think the news media so far has reported on the refugee situation?" The scale had 7 points, ranging from 1 (not good at all) to 7 (very good; Wave $1, M=4.22$, $S D=1.48$; Wave 2, $M=3.89, S D=1.45)$.

Noelle-Neuman (1984) raised the question of the importance of personal traits related to the spiral of silence phenomenon (Neuwirth et al., 2007; Scheufele \& Moy, 2000). Controlling some of these aspects by inclusion in the analysis were political interest, education, gender, and age.

Political interest. A respondent's political interest was measured by the 4-point-scale question "How interested are you in politics?" ranging from 1 (great interest) to 4 (no interest). The panel consisted of respondents with a greater interest in politics compared with the general 
public $(M=1.74, S D=0.66)$. This is related to the recruitment process and the questions asked in the panel, where societal issues dominated.

Education. In the survey, respondents answered a question about their highest level of education with fixed response alternatives (only elementary school; high school, less than 3 years; high school, 3 years or longer; postsecondary education [not university], less than 3 years; postsecondary education [not university], 3 years or longer; college/university, less than 3 years; college/university, 3 years or longer; $\mathrm{PhD}$ ). Even if the scale was ordinal, it was treated as interval in the analysis. The sample contained a larger number of people with college/university educations compared to the overall Swedish population $(M=6.91, S D=1.87)$.

Gender. This variable is measured by a self-reported question with three alternatives: woman, man, and other. Only four respondents chose the last option, and they were excluded from the analysis. The sample had a larger proportion of male respondents compared with the general population $(M=1.52, S D=0.50)$.

Age. Age was measured by the panelists' self-reported years of birth. The sample contained respondents aged between 18 and 72 years $(M=47, S D=13.99)$, which means that the sample contained more middle-aged and fewer young ( $<30$ years) and old ( $>70$ years) people compared with the population as a whole.

\section{Results}

The results in Table 1 indicate strong support for the proposed difference in the preparedness to give voice to opinions about the refugee crisis dependent on to whom a person talks. Overall, respondents are willing to express their opinions among family and friends, and the policy change did not change this attitude at all (Wave 1, $M=4.56$; Wave 2, $M=4.57$ ). As predicted in $\mathrm{H}_{4}$, respondents are a little less comfortable speaking out on this issue when talking to their colleagues and classmates, and over time, they tend to be less willing to express their opinions (Wave 1, $M=3.87$; Wave 2, $M=3.79$ ). But even after the policy change, a majority feel they can express their opinions when talking to people they meet at work or school.

This tendency is even clearer when asking about talking to people 


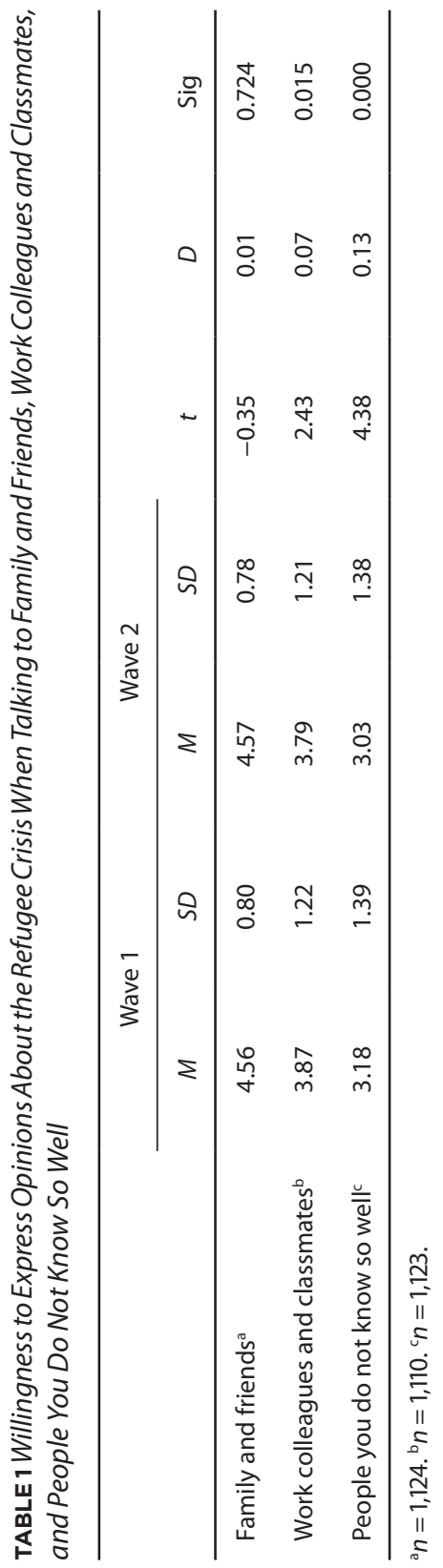


respondents do not know so well, both in terms of generally being less willing to speak out and changing toward being more silent after the policy change (Wave 1, $M=3.18$; Wave 2, $M=3.03$ ). On this general level, we therefore discover a significant tendency toward a more silenced public opinion, in terms of being willing to express opinions outside the family setting. Even so, the effect size $(d=.013, d=.07)$ indicates that the magnitude of the policy change on the willingness to speak opinions in public is rather low. It should also be noted that a majority of all respondents feel they can talk about the refugee crisis even if they talk to people they do not know so well, both before and after the policy change.

But are these tendencies uniform, or do they, as $\mathrm{H} 1, \mathrm{H} 2$, and $\mathrm{H} 3$ predicted, depend on the opinions about the refugee issue among the respondents? In Table 2, the analysis is separated among those who support a generous and a more restrictive refugee policy.

Moving on to the first (H1) hypothesis, we expected to find a correlation between supporting the government policy on the refugee issue and a willingness to speak out. However, the results show that those favoring a more generous refugee policy to a larger extent are willing to express their opinions about the refugee crisis, both before and after the policy change (family and friends, $M=4.86 / 4.81$; work colleagues and classmates, $M=4.48 / 4.30$; people you do not know so well, $M=3.97 / 3.68)$. The difference compared with respondents favoring a more restrictive policy is significant, where a clear majority instead are less comfortable expressing their opinions (family and friends, $M=4.33 / 4.37$; work colleagues and classmates, $M=3.33 / 3.37$; people you do not know so well, $M=2.46 / 2.46)$. On the basis of these two measurement points, it seems like those supporting a more restrictive policy are less likely to express their opinions, even if the policy has changed, favoring their position. H1 can therefore only be partly supported.

The second (H2) and third (H3) hypotheses focused on changes of expressing opinions, not the majority/minority position. $\mathrm{H} 2$ must be rejected because there was no change among those supporting a restrictive policy before and after the policy change, independent of whom they talk to. Even if the policy change supported their opinions, they 


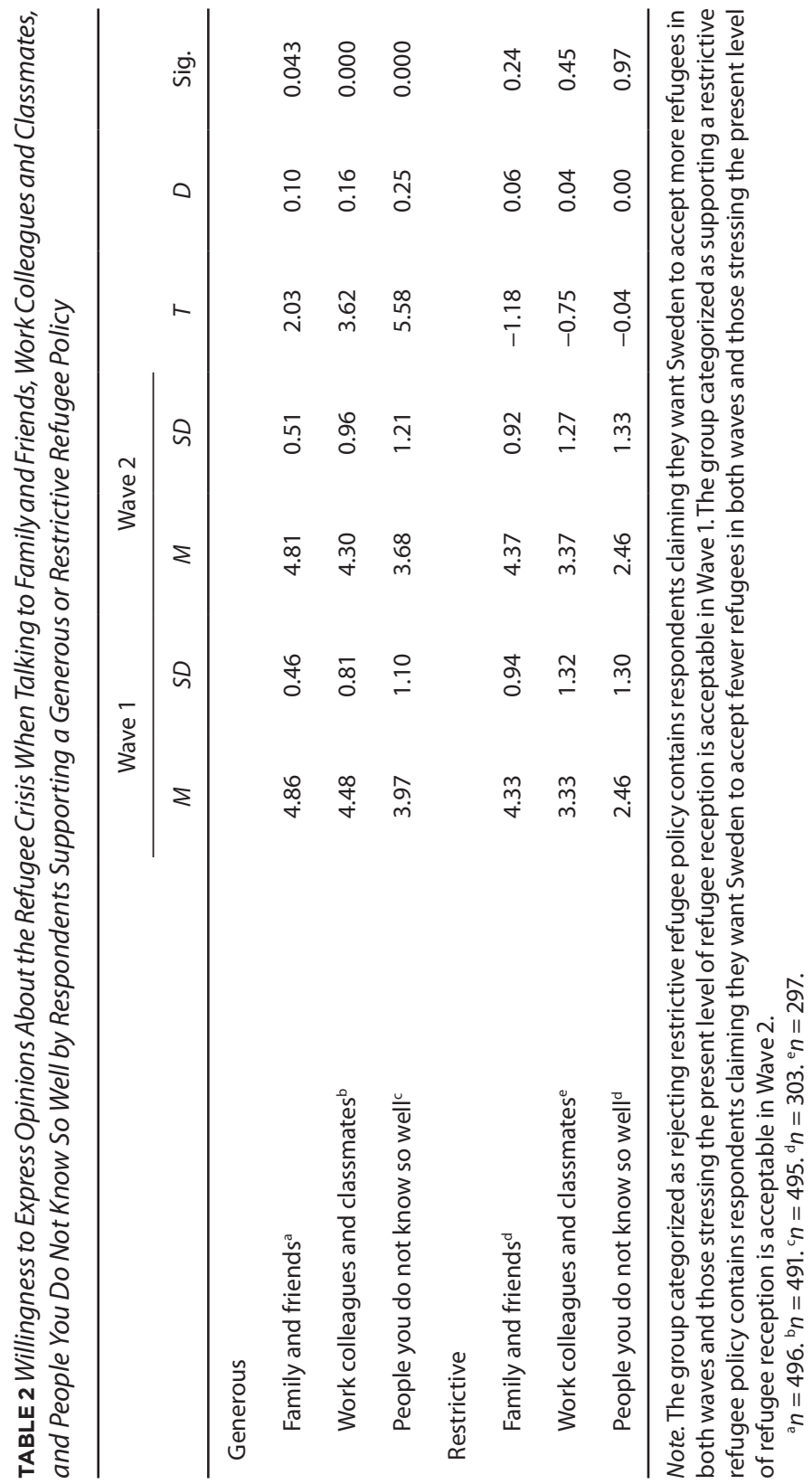


TABLE 3 Predictors That Impact the Willingness to Express Opinions About the Refugee Crisis in Conversations with Family and Friends, Work Colleagues and Classmates, and People You Do Not Know So Well

\begin{tabular}{|c|c|c|c|}
\hline & $\begin{array}{l}\text { Willingness to } \\
\text { speak out before } \\
\text { policy change }\end{array}$ & $\begin{array}{l}\text { Willingness to speak } \\
\text { out after policy } \\
\text { change }\end{array}$ & $\begin{array}{l}\text { Decreased } \\
\text { willingness to } \\
\text { speak out }\end{array}$ \\
\hline \multicolumn{4}{|l|}{ Family and friends } \\
\hline Own opinion (generous policy) & $.33^{* * *}$ & $.29^{* * *}$ & $-.11^{* *}$ \\
\hline Media congruency & .03 & $.07^{*}$ & -.04 \\
\hline Political interest (low) & -.01 & $-.08^{* *}$ & .06 \\
\hline Education (high) & -.07 & $-.07^{*}$ & .00 \\
\hline Gender (woman) & -.07 & -.06 & .03 \\
\hline Age & .02 & .06 & -.04 \\
\hline Adjusted $R^{2}(\%)$ & 10 & 9 & 1 \\
\hline$N$ & 816 & 818 & 815 \\
\hline \multicolumn{4}{|l|}{ Work colleagues and classmates } \\
\hline Own opinion (generous policy) & $.48^{* * *}$ & $.43^{* * *}$ & -.01 \\
\hline Media congruency & $.08^{*}$ & $.12^{* * *}$ & .02 \\
\hline Political interest (low) & -.03 & $-.10^{* *}$ & $.08^{*}$ \\
\hline Education (high) & -.04 & $-.10^{* *}$ & .04 \\
\hline Gender (woman) & .01 & .02 & -.01 \\
\hline Age & .04 & .04 & .00 \\
\hline Adjusted $R^{2}(\%)$ & 20 & 12 & 0 \\
\hline$N$ & 815 & 811 & 807 \\
\hline \multicolumn{4}{|l|}{ People you do not know so well } \\
\hline Own opinion (generous policy) & $.50^{* * *}$ & $.45^{* * *}$ & $.12^{* *}$ \\
\hline Media congruency & $.11^{* *}$ & $.09 *$ & .05 \\
\hline Political interest (low) & -.04 & $-.09 *$ & .06 \\
\hline Education (high) & .03 & -.05 & .02 \\
\hline Gender (woman) & -.02 & -.06 & -.03 \\
\hline Age & .04 & -.01 & $.08^{*}$ \\
\hline Adjusted $R^{2}(\%)$ & 28 & 19 & 2 \\
\hline$N$ & 816 & 817 & 814 \\
\hline
\end{tabular}

Note. Values are ordinary least squares, standardized regression coefficients. The dependent variables are created by computing the variable willingness to speak out in the two waves, where respondents could be more/less willing to speak out. The dichotomized variable for decreased willingness to speak out comprises those less inclined to express their opinions compared with those having the same opinion in both waves and those being more motivated to speak out. The media congruency measure is the absolute difference in opinion about the media reporting and respondents' own issue opinions in both waves. Tests to see if the data met the assumption 
of collinearity indicated that multicollinearity was not a concern (values ranging between the four regression models, own opinion, tolerance $=.78-.82$, VIF $=1.22-1.28$; media congruency, tolerance $=.85-.90, \mathrm{VIF}=1.12-1.18$; political interest, tolerance $=.93-.94, \mathrm{VIF}=1.06-1.07$; education, tolerance $=.90-.91$, VIF $=1.05-1.10$; gender, tolerance $=.88-.89, \mathrm{VIF}=1.13$; age, tolerance $=.95$, VIF $=1.05-1.06)$.

${ }^{*} p<.05 .{ }^{* *} p<.01 .{ }^{* * *} p<.001$.

still felt hesitant to speak out in public about their opinions. Moving on to $\mathrm{H}_{3}$, we find clear support for what was expected. Respondents supporting a more generous policy have to some extent been silenced. After the policy change, significantly fewer respondents were willing to express their views on the refugee crisis. This can be found independent of social sphere, even if the tendency is clearly related to social groups outside family and close friends.

To further examine the mechanisms of the spiral of silence, Table 3 shows to what extent changes in the willingness to speak out are related to a person's own opinion and perception of media congruency. We also control the results by demographics, which sometimes are treated as personal traits with a possible influence on willingness to speak out in public.

The results of three regression models are shown in Table 3, where the dependent variable measures respondents' willingness to express their opinions, both at and between the two measurement points. The first two models analyze the data as cross-sectional data to see if media congruency affects the predisposition to speak out before and after the policy change. The last model analyzes changes and whether media congruency has an impact on opinion change (i.e., less willing to express opinions).

In all three social spheres, we find that issue position has an impact on the respondents' willingness to reveal their opinions about the refugee crisis, both before and after the policy change (family and friends, $\beta=.33 / .29$; work colleagues and classmates, $\beta=.48 / .43$; people you do not know so well, $\beta=.50 / .44$ ). The more a person supports a generous policy, the more willing he or she is to speak out. This is the same tendency we saw in Tables 1 and 2.

Also, media congruency has an impact on the tendency to speak out. Respondents who are more critical toward the media reporting also seem to be less inclined to reveal their opinions. This is found in 
all social spheres after the policy change (family and friends, $\beta=.07$; work colleagues and classmates, $\beta=.12$; people you do not know so well, $\beta=.09$ ). Before the change of policy, the effect of media congruency was significant for talking to people at work and in school, $\beta=.08$, and strangers, $\beta=.11$, but not in discussions among family and friends, $\beta=.03$.

Political interest also affected this opinion, especially after the policy change. Those less interested in politics seem to be more inclined to hide their opinions, independent of whom they talk to (family and friends, $\beta=-.08$; work colleagues and classmates, $\beta=-.10$; people you do not know so well, $\beta=-.09$ ). The same holds for lower educated respondents, but only when speaking with family members and close friends, $\beta=-.08$, and people at work and in school, $\beta=-.10$.

When analyzing the change of willingness to speak out, the results indicate overall a weak relationship between the proposed variables (i.e., low explained variance). The most important factor is a person's own opinion on the issue, but the effect goes in different directions, depending on social sphere. Among family and friends, we find that supporting a more generous policy does not lead to a decreased inclination to reveal opinions, $\beta=-.11$, but it does so when talking to strangers, $\beta=.12$. Moreover, there seems to be no direct effect on the inclination of changes in speaking out related to how news media performance was evaluated and the respondents' own opinions (media congruency). If someone changed his or her willingness to express his or her views, this change may not be related to the person's perceptions of news media reporting. This does not, of course, rule out a possibility of indirect media impact in line with the spiral of silence theory. As said before, the media effect in the spiral of silence theory might be unconscious.

The other predictors show no significant effect, except that increasingly age seems to be related to less willingness to talk about the refugee issue with strangers. Being a man or a woman, being low or highly educated, or having an interest in politics does not seem to matter. 


\section{Discussion}

The spiral of silence is one of the most influential media effect theories of the last half-century. Noelle-Neuman's theory on how the media influences people's willingness to speak their minds in public has been subject to many studies all over the world. However, the theory has been criticized in terms of conceptualization (Neuwirth et al., 2007), design (Matthes \& Hayes, 2016), and generalization (Scheufele \& Moy, 2000).

The present study analyzed changes over time in the willingness to express opinions about the refugee crisis in Europe using a two-wave Web-panel survey in Sweden in 2015-2016. In focus was the impact of the changing government policy, which moved from a generous refugee policy toward a more restrictive policy.

The posed hypotheses had mixed support. Government changes in policy toward a more restrictive refugee policy did not change the overall picture. Those supporting a more restrictive policy were still less inclined to speak their true opinions about the refugee crisis, even if the policy had changed in their favor. On the other hand, respondents supporting a more generous refugee policy seemed to be more cautious about expressing their opinions about the refugee crisis when talking to strangers after the policy change. The tendency to hide opinions about the refugee crisis was stronger when talking to strangers and less pronounced in relation to work colleagues and classmates, and a vast majority felt they could talk about the issue with family and friends.

When analyzing the research question about the extent to which media congruency affects willingness to speak out over time, there was no such influence. It is, however, important to understand the difference between analyzing changes and the situation at a given moment. Media congruency had a clear impact on the willingness to share opinions, both before and after the policy change, but media congruency did not affect changes in preferences to talk about the refugee crisis before and after the policy change.

What might need further discussion in relation to the spiral in the spiral of silence theory is the time lag in the process. Most studies include, in line with Noelle-Neuman's suggestions about capturing dynamics of the opinion climate, measures used to understand 
respondents' perceptions of whether their opinions are likely to become majority or minority (Gearhart \& Zhang, 2015; Jeffres, Neuendorf, \& Atkin, 2010; Noelle-Neuman, 1984). People who feel their opinions are about to reflect the majority position are more inclined to speak out. The change in the predisposition to express opinions on the refugee issue follows this pattern for those rejecting a restrictive policy but not among those supporting a restrictive policy. Five months after the policy change, one could expect that those persons who were more critical about accepting refugees would be more eager to speak out. But according to the results, we do not see this development. In line with what previous research has shown in asking about opinions being on the rise or in decline, we should have seen such a change.

Situational explanations can be proposed to explain this lack of willingness to speak out among those supporting a restrictive refugee policy. Even if the policy has changed, many might still be uncertain if this opinion is shared among the general public, not least because the government made the decision with regret and claimed the restrictive policy was not intended to be permanent. A fear of stigmatization might therefore still be possible. Because the restrictive policy has not changed since April 2016, more measurement points could clarify if there is a time lag in processes of the spiral of silence. Over time, those favoring a more restrictive policy might speak out, but the opinion change process might be slower than 5 months. To further understand the dynamics of the spiral of silence, one might therefore need more measurement points. This also highlights that there might be different dynamics depending on respondents' perceptions of whether they are in a majority or minority position. Regarding the refugee issue, willingness to speak out first changes among those who have the majority position. They feel uncertain and become more silent as the refugee policy changes to a position that is different from their own. Maybe those having the minority position will change, but it will take longer before they dare to speak out. They are not sure this change of policy position will last, and even if there is a change of tone in the news media, reporting the process of experiencing a majority position might take a while.

This might indicate there are different time lags in the spiral of silence dynamics depending on if one is to become part of the majority 
or minority opinion. Further research on the spiral of silence would be beneficial to better emphasize the dynamics to be able to understand how the spiral in the spiral of silence actually works. Other shortcomings of the present study can also be discussed. In terms of generalizability, a partly recruited panel of respondents might overestimate the willingness to express opinions. Participating in a panel with surveys predominately about politics will be more attractive to people interested in politics, and dropout from the panel will be higher among those less interested in politics.

\section{Conclusion}

Let us at last move back to where we started. What are the consequences for crisis communication and, more specifically, citizens' sense making of a crisis related to the spiral of silence? In the introductory section of this article, concerns were raised about the possible difficulty discussing a controversial issue, such as the refugee crisis, in the sense-making process. Strategies proposed by convergence theory were addressed in terms of how people find and use information from different sources, not least in discussion with other people to handle competing information (Anthony et al., 2013; Sellnow et al., 2009). The present study does not support the raised concerns. It seems like most people are willing to discuss a controversial issue among both family and friends and people with whom they work and go to school. People even dare to expose their opinions about a value-laden issue like the refugee crisis to people they do not know well. Even if there is a tendency toward a more silenced public opinion, it is not alarming when talking to family and friends. So even if there is a spiral of silence, it does not seem to undermine citizens' sense-making processes in times of crisis.

Bengt Johansson, $\mathrm{PhD}$, is a professor in journalism and mass communication at the University of Gothenburg in Sweden. His research focus is on crisis communication and political communication. He is vice chair for the section Political Communication Research at the IAMCR. 


\section{ORCID}

Bengt Johannson (i) https://orcid.org/oooo-0oo2-8980-1677

\section{Notes}

1. See https://www.migrationsverket.se/

2. https://www.migrationsverket.se/

3. See http://eur-lex.europa.eu

4. For more information about the panel, see http://www.lore.gu.se/

\section{References}

Anthony, K. E., Sellnow, T. L., \& Millner, A. G. (2013). Message convergence as a message-centered approach to analyzing and improving risk communication. Journal of Applied Communication Research, 41, 346-364. https://doi.org/10.1080/00909882.2013.844346

Bennet, L. W. (1990). Toward a theory of press-state relations in the United States. Journal of Communication, 56, 467-485. https://doi.org/10.1111/j.146o $-2466.1990 . t b 02265 . x$

Berrington, A., Smith, P., \& Sturgis, P. (2006). An overview of methods for the analysis of panel data. Southampton, England: ESRC National Centre for Research Methods, University of Southampton.

Boin, A., t'Hart, P., \& McConnell, A. (2009). Crisis exploitation: Political and policy impacts of framing contests. Journal of European Public Policy, 16, 81-106. https://doi.org/10.1080/13501760802453221

Boin, A., t'Hart, P., Stern, E., \& Sundelius, B. (2005). The politics of crisis management: Public leadership under pressure. Cambridge, England: Cambridge University Press.

Donsbach, W., Salmon, C. T., \& Tsfati, Y. (2016). The legacy of spiral of silence theory: An introduction. In W. Donsbach, C. T. Salmon, \& Y. Tsfati (Eds.), The spiral of silence: New perspectives on communication and public opinion (pp. 1-18). New York, NY: Routledge.

Frandsen, F., \& Johansen, W. (2017). Organizational crisis communication: A multivocal approach. London, England: Sage. 
Gearhart, S., \& Zhang, W. (2015, December 3). Same spiral different day? Testing the spiral of silence across different issue types. Communication Research. https://doi.org/10.1177/oo93650215616456

Ghersetti, M., \& Odén, T. (in press). Flyktingkrisen i medierna och opinion. Stockholm, Sweden: MSB.

Glynn, C. J., Hayes, A., \& Shanahan, J. (1997). Perceived support for one's opinions and willingness to speak out: A meta-analysis of survey studies on the "spiral of silence." Public Opinion Quarterly, 61, 452-463. https:// doi.org/10.1086/297808

Glynn, C. J., \& Huge, M. E. (2016). Speaking in spirals: An up-dated metaanalysis of the spiral of silence. In W. Donsbach, C. T. Salmon, \& Y. Tsfati (Eds.), The spiral of silence: New perspectives on communication and public opinion (pp. 65-72). New York, NY: Routledge.

Green-Pedersen, C., \& Krogstrup, J. (2008). Immigration as a political issue in Denmark and Sweden. European Journal of Political Research, 47, 610-634. https://doi.org/10.1111/j.1475-6765.2008.00777.x

Gunther, A. C., \& Storey, J. D. (2003). The influence of presumed influence. Journal of Communication, 35, 199-215. https://doi.org/10.1111/j.1460-2466.2003 .tbo2586.x

Hampton, K. N., Rainie, L., Lu, W., Dwyer, M., Shin, I., \& Purcell, K. (2014). Social media and the "spiral of silence." Washington, DC: Pew Research Center.

Hayes, A. (2007). Exploring the forms of self-censorship: On the spiral of silence and the use of opinion expression avoidance strategies. Journal of Communication, 57, 785-802. https://doi.org/10.1111/j.1460-2466.2007.0 0368.x

Heath, R. L., \& O'Hair, H. D. (2010). The significance of crisis and risk communication. In R. L. Heath \& H. D. O'Hair (Eds.), Handbook of risk and crisis communication (pp. 5-30). New York, NY: Routledge.

Iyengar, S., \& Kinder, D. R. (1987). News that matters: Television and American opinion. Chicago, IL: University of Chicago Press.

Jeffres, L. W., Neuendorf, K. A., \& Atkin, D. (2010). Spirals of silence: Expressing opinions when the climate of opinion is unambiguous. Political Communication, 16, 115-131. https://doi.org/10.1080/105846099198686

Johansson, B. (2017). Medievalrörelsen 2014: En valrörelse i skuggan av en orolig omvärld. In L. Truedsson \& B. Johansson (Eds.), När makten står 
på spel: Journalistik i valrörelser (pp. 22-57). Stockholm, Sweden: Institutet för mediestudier.

Louis, W. R., Duck, J. M., Terry, D. J., \& Lalonde, R. N. (2010). Speaking out on immigration policy in Australia: Identity threat and the interplay of own opinion and public opinion. Journal of Social Issues, 66, 653-672. https:// doi.org/10.1111/j.1540-4560.2010.01669.x

Matera, F. R., \& Salwen, M. B. (1992). Support for the Radio Marti among Miami's Cubans and non-Cubans. International Journal of International Relations, 16, 135-144. https://doi.org/10.1016/o147-1767(92)90036-T

Matthes, J., \& Hayes, A. T. (2016). Methodological conundrums in spiral of silence research. In W. Donsbach, C. T. Salmon, \& Y. Tsfati (Eds.), The spiral of silence: New perspectives on communication and public opinion (pp. 54-65). New York, NY: Routledge.

Matthes, J., Morrison, K. R., \& Schemer, C. (2010). A spiral of silence for some. Communication Research, 37, 774-80o. https://doi.org/10.1177 /0093650210362685

McDonald, D. G., Glynn, C. J., Kim, S.-H., \& Ostman, R. E. (2001). The spiral of silence in the 1948 presidential election. Communication Research, 28, 139-155. https://doi.org/10.1177/009365001028002001

Moy, P., Domke, D., \& Stamm, K. (2001). The spiral of silence and affirmative action. Journalism and Mass Communication Quarterly, 78, 7-25. https:// doi.org/10.1177/107769900107800102

Neuwirth, K., Frederick, E., \& Mayo, C. (2007). The spiral of silence and fear of isolation. Journal of Communication, 57, 450-468. https://doi .org/10.1111/j.1460-2466.2007.00352.x

Noelle-Neuman, E. (1984). The spiral of silence: Public opinion-our social skin. Chicago, IL: University of Chicago Press.

Ohlsson, J., Ekengren Oscarsson, H., \& Solevid, M. (Eds.). (2016). Ekvilibrium. Gothenburg, Sweden: SOM-institutet, Göteborgs Universitet.

Oshagan, H. (1996). Reference group influence on opinion expression. International Journal of Public Opinion Research, 8, 335-354. https://doi .org/10.1093/ijpor/8.4.335

Perloff, R. M. (2015). A three-decade retrospective on the hostile media effect. Mass Communication and Society, 18, 721-729. https://doi.org/10.1080/15 205436.2015.1051234

Scheufele, D., \& Moy, P. (2000). Twenty-five years of the spiral of silence: A 
conceptual review and empirical outlook. International Journal of Public Opinion Research, 12, 3-28. https://doi.org/10.1093/ijpor/12.1.3

Schulz, A., \& Roessler, P. (2012). The spiral of silence and the Internet: Selection of online content and the perception of the public opinion climate in computer-mediated communication environments. International Journal of Public Opinion Research, 24, 346-367. https://doi.org/10.1093/ijpor/edso22

Seeger, M. L., \& Sellnow, T. W. (2016). Narratives of crisis: Telling the stories of ruin and renewal. Stanford, CA: Stanford University Press.

Sellnow, T. L., Ulmer, R. R., Seeger, M. W., \& Littlefield, R. S. (2009). Effective risk communication: A message-centered approach. New York, NY: Springer.

Sellnow, T. W., \& Seeger, M. W. (2013). Theorizing crisis communication. Chichester, England: John Wiley.

Shamir, J. (1997). Speaking up and silencing out in the face of a changing climate of opinion. Journalism \& Mass Communication Quarterly, 74, 602-614. https://doi.org/10.1177/107769909707400313

Sides, J., \& Citrin, J. (2007). European opinion about immigration: The role of identities, interests and information. British Journal of Political Science, 37, 477-504. https://doi.org/10.1017/Sooo7123407000257

Ulmer, R. R., Sellnow, T. L., \& Seeger, M. L. (2007). Effective crisis communication: Moving from crisis to opportunity. Thousand Oaks, CA: Sage.

Vigsø, O., \& Odén, T. (2016). The dynamics of sensemaking and information seeking in a crisis situation. Nordicom Review, 37, 71-84. https://doi .org/10.1515/nor-2016-0003

Zaller, J. (1992). The nature and origins of mass opinion. Cambridge, England: Cambridge University Press. 